\title{
A Turtle's Journey: Strengthening Indigenous Research Capacity through Mentoring
}

\author{
Heron Loban \\ School of Law, James Cook University, Cairns
}

\begin{abstract}
Mentoring can provide significant benefits to both the mentor and the mentee. Such relationships can develop organically, or through a matching process as part of a mentoring program, as structured mentoring. This paper examines the advantages and disadvantages of both types of mentoring in the context of strengthening Indigenous research capacity. The author reflects on her own experiences of being mentored as an Indigenous academic and researcher and the lessons that can be learned from this experience. With reference to the literature and author's case study, the paper will focus on the potential professional, personal and social impacts of mentoring relationships for Indigenous academics.
\end{abstract}

A hatchling green turtle is an endangered species and has to contend with many predators on its instinctual journey from sand to sea. Its survival is dependent on its ability to negotiate its predators and the elements of nature, by using its special compass to guide it safely. The seagull, crab, goanna, fish and shark all wait to make a meal of the hatchling. Some hatchlings make it to the sea with torn and damaged flippers. The survival rate of hatchlings is very low.

If the hatchling had a way of knowing a safe time to leave the nest, or how to navigate around the predators, rocks and sand dunes, its chances of survival would be much higher.

Like the turtle hatchlings, academics in their early years at university need the support and guidance of more experienced and successful academics to survive and thrive. A lack of confidence, direction and understanding of the politics of academia means significant numbers are hindered or fail to reach their goals. This is the story of an Indigenous academic.

\section{Introduction}

Tndigenous employees at universities in Australia are facing many challenges in their efforts to cement their place in higher education. They include amongst other matters uneven university commitment to Indigenous knowledges and considerable workload issues. There are too few Indigenous academics and too few Indigenous $\mathrm{PhD}$ candidates. According to Andersen, Bunda and Walter (2008, p. 6) 'the presence of Indigenous staff within all facets of university life is centrally connected to Indigenous student success at both undergraduate and postgraduate level... [Yet while] [u]niversities are often major employers within their regions 
their record of employing Indigenous staff is poor'. Fredericks (2009) lists a litany of issues affecting the success of Indigenous academics in Australian universities.

So, what can an Indigenous person do to improve her or his chances of success in the academic arena? What can universities do to redress this inequity? Good mentoring can assist with the retention of academics and the development of their research skills. This paper will look at the role of universities in Indigenous academic success with reference to the literature and a personal reflection case study on the value of mentoring in facilitating this success.

\section{A Gap in the Literature}

Whilst the need for increasing numbers of Indigenous academics appears to be well documented at least if not well executed so far, there is a scarcity of literature on the mentoring experience of Indigenous academics in the context of recruitment and retention goals or otherwise.

Indeed, there is a paucity of work in respect of mentoring in culturally diverse contexts generally. This is an issue noted in the American context by Noonan et al (2007, p. 260) who suggested the need for more research in this area because of the increasing cultural diversity of university populations. In this regard, Westlander (2009, p. 86) also noted the lack of literature inclusive of ethnic minorities. Research on mentoring programs to date has been predominantly based on 'white' participants.

\section{What is mentoring?}

What the available literature does do is uncover a considerable range of meanings of the term 'mentor' which are useful in determining what types of mentoring would be suitable for Indigenous academics. 'Mentor' has been used in a range of situations including the vocational education training (Barratt-Pugh, 2012) and universities (Hemmings, 2012). The descriptors attached to a mentor and the associated mentoring process and behaviours, have been strongly influenced by the intended audience, organisation and purpose. It is therefore useful to tease out these differences in interpretations, identify commonalities of meaning and outline the core attributes of a mentor and a mentee as a starting point for discussions in the university context and mentoring Indigenous academics, particularly for research success. Investing time in determining what mentoring is a worthwhile, front-end process.

The Oxford dictionary defines a mentor as 'an experienced and trusted adviser' and 'an experienced person in a company or educational institution who trains and counsels new employees or students'. At the simplest level, mentoring involves two individuals, in a formal or informal process, with the one, the mentor, providing instruction, with a view to assisting in the professional development of the other, the mentee.

In one study of academics, career mentors were found to be important to career success and professional development (Madison, Knight and Watson, 1993, p. 80). Mentors acted as 'confidantes who personalise role modelling' and gave their knowledge and expertise to help the mentee 'understand and break down the social and political barriers' of academia (Madison, Knight and Watson, 1993, p. 83). Research by Noonan, Black and Ballinger (2007, p. 255) noted a level of consistency in the language used to describe a mentor, with variations on emphasis. Their research highlighted differences in the process of formal and informal mentoring, placing mentors on a continuum from helpers and guides, through to 
knowledgeable, collegial, experienced, professionals to facilitators, instrumentals, teachers and collaborators. They (Noonan, Black and Ballinger, 2007, p. 252) argued the importance of scaffolding to assist and progress the mentee from being on the fringe of academia to becoming more of a university 'insider'.

Interestingly, whilst numerous studies on the mentoring process have identified 'relationship' as an integral part of the process, they failed to specify or identify the type of relationship involved, that is, whether it is formal, existing as part of a program organised by a third party, or informal, where the relationship is natural and grounded on a voluntary basis, with the agreement of both parties (Westlander, 2009, p. 88; Haggard, Dougherty, Turban and Wilbanks, 2010, p. 282; Burgess and Dyer, 2009). Studies on professional mentoring, noted several consistent constructs, in particular the concept of relationships was identified. This was acknowledged as one of the key components of the mentoring experience. This construct affected and impacted on the mentors support and on the mentees self-confidence (Hemming, 2012, p. 181) in the mentor-mentee relationship. The mentoring process was based on a relationship between mentor (more experienced) and mentee (less experience) and required a level of connectedness. This connectedness was alluded to as an important aspect of a 'meaningful and nurturing' relationship in Hemming's work (2012, p. 173). It was also viewed as intrinsic to an active 'reciprocal relationship' (Turnbull, 2010, p. 574) and formed part of a 'reciprocal collegial relationship' (Noonan, Black and Ballinger, 2007, p. 258). Madison, Knight and Watson (1998, p.78) articulated that mentoring involved a 'high level human relationship of some significance'.

\section{Qualities of a 'Good' Mentor}

Who then could, or should, mentor Indigenous academics for professional success? An exploration of the research literature on the characteristics and benefits of a 'good' mentor recognised and acknowledged that not all academics experienced in their field, will be effective mentors (Darwin and Palmer, 2009, p. 126). Turnbull (2010, p. 575) noted that qualities most valued by mentees were 'respect, honesty, trust, integrity and credibility'. A 'good' mentor provided support in the form of 'positive feedback' - essential to a meaningful and nurturing relationship and aimed at improving 'performance and potential' (Burgess and Dyer, 2009, p. 6).

Good mentors have been described as assisting in breaking down social and political barriers and facilitating the mentee into leadership roles and senior positions within the university sector. Mentoring has acted as a tool of socialisation (Hutchinson, 2002, p. 176) for an individual modeling behaviours, attitudes and skills to help the mentee in 'achieving competence, confidence and a professional identity' (Burgess and Dyer, 2009, p. 6). It has also facilitated the passing on of the 'accumulated wisdom' of working in that environment (Burgess and Dyer, 2009, p. 6). Learning the unwritten social rules and the strategies for success, was seen as part of a shared language through a recognised social network that helped the mentee learn the traditions, culture, practices and values of the discipline and institution (Noonan, Black and Ballinger, 2007, p. 252). Madison, Knight and Watson (1993, p. 88) attributed 'increased self-confidence; role acceptance, socialisation into academia; and achievement of scholarly activities' to a successful mentoring process. 


\section{Research Mentoring}

It's 'publish or perish' - for Indigenous and non-Indigenous academics alike. So, how can mentoring enhance an Indigenous academic's research performance? In the academic setting, the work of Hemming (2012, p. 178) and Irvine, Moerman and Rudkin (2010) emphasised the importance of the mentor assisting the mentee, to not only advance her or his career by enhancing learning but also to build networks and advocate for research in the form of published papers. However, much of the available university context literature deals with mentoring for teaching as opposed to mentoring for publishing and research. Yet, it is arguably research activity that is valued in promotion and academic progression processes.

Teaching, however, has been seen as a real impediment to publishing and research. Hemming (2012, p. 174) noted in his study that the heavy teaching loads and the associated preparation and delivery to the student population, had a significant impact on the ability of early career academics to engage in research activities. Turnbull (2010, p. 575) argued that although mentees saw the importance of increased levels of scholarship, both 'personally and professionally' the issue of the 'valuing and the prioritising of teaching was at odds' with the emphasis placed on research. Furthermore, 'high teaching workloads correlated directly' with low outputs in research. Achieving a balance was a common conundrum. Mentors who assisted their mentees in appreciating and understanding the 'rules of the research game' were able to foster mentees confidence (Hemming, 2012, p. 179). Hemming (2012, p. 172) suggested 'research self - efficacy' was an important aspect of mentees' success in research and publishing, with mentors assisting in this process. Research capability and proven capacity in developing research knowledge and its associated skills, coupled with modeling good practice was seen as critical to a successful mentor-mentee relationship (Hemming, 2012, p. 173). Hemming (2012, p. 173) further noted that research and writing skills may be improved and enriched through 'co-authorship' In addition a good mentor assisted the mentee as an early career academic with 'track record' and researcher identity (Scaffidi and Berman, 2011).

\section{A Case Study and Personal Reflection}

In mentoring, as with any relationship, the parties are best-placed to judge success. Mentee reflections are strongly influenced by their own perspective. This brings the author to her own experience as a mentee, as part of a fellow-in-residence scheme at a university research institute, working on a project under the guidance of a professor acting as the mentor. For the purposes of this case study, the author will be referred to as the "mentee" and the professor as the "mentor".

As an early career academic, at first, the mentee was unsure about whether the fellow-inresidence program was intended for 'new' academics. The mentee, however, had the benefit of working with the mentor before and in speaking to him about the fellow-in-residence program was encouraged to apply to the program. Secondment to the fellow-in-residence program was a negotiation process with the mentee's head of school. Prior to submitting the application the mentee had to reach an agreement with the head of school regarding her teaching load. The mentee agreed to teach one subject over the Christmas/New Year period and buy-out the other subject with funds in her individual research account accumulated over time from consultancies, plus a partial contribution from the faculty. The mentee's application for the fellow-in-residence program was successful and so began the secondment (and mentoring opportunity). 
At the beginning of the fellow-in-residence the mentor and mentee agreed to set about achieving three key outcomes as part of the secondment. The agreed goals were to publish an article in a refereed journal; to submit an external grant application; and to apply for enrolment in a PhD. Two of these goals were achieved. The mentee submitted an application for enrolment in the university $\mathrm{PhD}$ program and was accepted. The mentee then submitted an application for a competitive, external grant to carry out participant interviews at one of the sites for the PhD and was successful. Whilst the mentee did not have an article published during the fellow-in-residence the mentee has since published numerous articles related to the $\mathrm{PhD}$ topic and one co-authored with the mentor (and others).

While a fellow-in-residence the mentee was also able to access and use the administrative services provided by the research institute. For example, applying for grant funding and submitting tenders is a skill and one which an early career academic generally has limited experience in doing. As the staff at the research institute prepared these types of documents frequently the mentee was able to gain new insight into how to write such documents and create efficiencies to meet the related deadlines. As a fellow-in-residence the mentee became known to many of the research institute's staff. As a result of this the mentee has since been approached a number of times to submit tenders for consultancies with the research institute. The tenders have been unsuccessful to date but the continued experience has been invaluable.

Finally, and perhaps most importantly the fellow-in-residence program was a structured mentoring program. In a small school where teaching is a significant component of an academic's workload the fellow-in-residence program provided a space to learn new research skills, to build professional networks, to develop administrative experience with processes such as tender writing, and to achieve research goals with the support and guidance of a mentor. From the mentee's point of view, a strong feature of the fellow-in-residence program was its help to build partnerships and relationships for the mentee across the university. It created ties between the mentee and other academics and promoted and supported research excellence.

There was also an unexpected personal outcome for the mentee. The mentoring experience was so positive that it inspired the mentee to reach out and in turn mentor someone else - an Indigenous student. A new mentor-mentee relationship developed, informally. The mentor (Indigenous academic) and mentee (Indigenous student) co-authored a conference paper abstract that was accepted, and then co-presented their ideas. The conference presentation was well-received.

\section{Conclusion}

This paper set out to look at the possible benefits for universities and Indigenous academics of structured or organic mentoring given the dearth of information available on mentoring Indigenous people in the university sector. Clearly, though, common understandings of the notion of mentoring and the characteristics of a good mentor have developed over time and its general benefits understood. The experiences, within the university sector and elsewhere, of others do show that mentoring is a success strategy that works and can be applied to the address the disparity in Indigenous academia, including any barriers that might present.

This paper contains a single case study. The limits of generalisability of this are acknowledged. However, the case study together with the literature outlining the gains than 
can be made for mentees in a mentoring relationship make a strong case for its inclusion in university approaches to increasing Indigenous people's participation in academia and for ongoing success. What universities must do is find the means and the ways to provide quality mentoring for Indigenous academics, specifically in the area of research and publishing.

This paper began with a story of the turtle.

Mentoring is not the sole solution to increasing numbers of Indigenous academics or improving the chances of success of Indigenous academics progressing to professor. But like the turtle, what mentors may provide is a way of knowing, navigating, surviving and succeeding in the university's tricky terrain.

\section{Works Cited}

Journal Articles

Andersen, C., Bunda, T. and M. Walter. "Indigenous Higher Education: The Role of Universities in Releasing the Potential”. The Australian Journal of Indigenous Education 37 (2008): 1-8.

Barratt-Pugh, L. "Mentoring the Next Researcher Generation: Reflections on Three Years of Building VET Research Capacity and Infrastructure”. International Journal of Training Research 10.1 (2012): 6-22.

Burgess, J. and S. Dyer. "Workplace Mentoring for Indigenous Australian: A Case Study". Equal Opportunities International 28.6 (2009): 465-485.

Darwin, A. and E. Palmer. "Mentoring Circles in Higher Education”. Higher Education Research and Development 28.2 (2009): 125-136.

Fredericks, B.L. "Race and Equality in Higher Education: A Harder Path for Indigenous Academics”. National Women's Journal Frontline 17 (2009): 14-15.

Haggard, D.L., Dougherty, T.W., Turban, D.B. and J.E. Wilbanks. "Who is a Mentor? A Review of Evolving Definitions and Implications for Research”. Journal of Management 37.1 (2011): 280-304

Hemmings, B. "Sources of Research Confidence for Early Career Academics: A Qualitative Study”. Higher Education Research and Development 31.4 (2012): 171-184.

Hutchinson, T. “Seeking Yoda: Mentoring Women Legal Academics”. Queensland University of Technology Law and Justice Journal 2.2 (2002): 175-197.

Irvine, H., Moerman, L. and K. Rudkin. "A Green Drought: the Challenge of Mentoring for Australian Accounting Academics”. Accounting Research Journal 23.2 (2010): 146171. 
Madison, J., Knight, B.A. and K. Watson. "Mentoring Amongst Academics in Australia: A Case Study”. Australian Educational Researcher 20.1 (1993): 77-83.

Noonan, M.J., Black, R. and R Ballinger. "Peer and Faculty Mentoring in Doctoral Education: Definitions, Experiences, and Expectations”. International Journal of Teaching and Learning in Higher Education 19.3 (2007): 251-262.

Scaffidi, A.K. and J.E. Berman. “A Positive Postdoctoral Experience is Related to Quality Supervision and Career Mentoring, Collaborations, Networking and a Nurturing Research Environment”. Higher Education 62.6 (2011): 685-698.

Turnbull, B. “Scholarship and Mentoring: An Essential Partnership?”. International Journal of Nursing Practice 16.6 (2010): 573-578.

Westlander, G. “Book Review”. International Journal of Evidence Based Coaching and Mentoring 7.2 (2009): 82-96.

Reports

Department of Employment, Education and Training and Bourke, E.A., Farrow, R. McConnochie, K. and A. Tucker. Career Development in Aboriginal Higher Education (1991). Web. 24 ${ }^{\text {th }}$ June 2013.

Universities Australia. Guiding Principles for Developing Indigenous Cultural Competency in Australian Universities (2011). Web. 24 ${ }^{\text {th }}$ June 2013. 